\title{
EDITORIAL
}

\author{
Masaaki Kawahashi
}

\section{Renovation of Journal of Visualization}

Published online: 8 January 2010

(C) The Visualization Society of Japan 2009

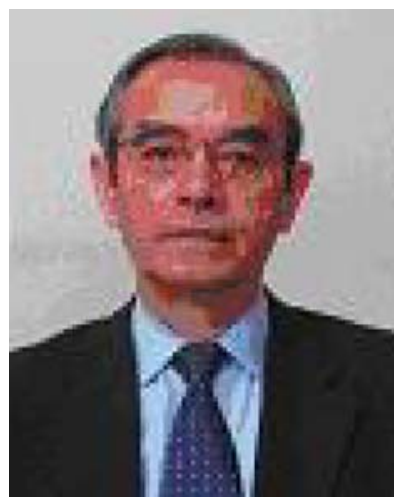

Professor Masaaki KAWAHASHI

Editor-in-Chief of Journal of Visualization

The Journal of Visualization has been renovated on 1 January 2010.

The Journal was founded in 1998 as a full color journal. In those days, the papers were published in black and white. However, the color images were very important to understand the visualized information. Then, the Editorial Board decided to publish the full-color printing journal. There were very few color journals in 1998.

After 12 years of continuous publication by the Visualization Society of Japan (VSJ), the Journal has become one of the top journals in the field of Visualization. The circumstances have also drastically changed. Almost all other journals are published online with color images.

In 2008, the VSJ decided the transfer of the publisher to Springer Verlag. Following the contract, the Journal of Visualization has been published by Springer Verlag from this volume, i.e., Volume 13.

The Editorial Board was also reconstructed for this renovation. I am the new Editor-in-Chief with the support of Eight Associate Editors. We would like to thank the previous Editorial Board Members for their efforts to improve the Journal, especially Prof. Nakayama, Prof. Tanida and Prof. Kobayashi, former Editorin-Chiefs. The new Editorial Board will also make great efforts to keep or improve the quality of the journal.

The scope of the journal is expanded to more wide fields. The scope includes Information Visualization, Data Visualization, Flow Visualization, System Visualization and so on. Any papers related to the VISUALIZATION will be published in this journal.

VISUALIZATION is the keyword to solve many problems in the 2010s, such as Global Warming, Energy Security, Knowledge Management and so on. The Journal of Visualization will be growing to be a world top journal in the field of Visualization.

M. Kawahashi $(\bowtie)$

Saitama University, 255 Shimo-okubo, Sakura-ku, Saitama 338-8570, Japan

E-mail: mkawa@mail.saitama-u.ac.jp 